\title{
Capturing the Benefits of Industry 4.0: A Business Network Perspective \\ Andreas Schroeder*
}

http://orcid.org/0000-0002-4051-9275

Aston University

Aston Triangle, Birmingham, UK

a.schroeder@aston.ac.uk

* corresponding author

\section{Ali Z. Bigdeli}

https://orcid.org/0000-0002-8128-0918

Aston University

Aston Triangle, Birmingham, UK

a.bigdeli@aston.ac.uk

\section{Carlos Galera Zarcos}

Coventry University

Priory St, Coventry, UK

ac6380@ coventry.ac.uk

\section{Tim Baines}

Aston University

Aston Triangle, Birmingham, UK

t.baines@aston.ac.uk 


\section{AbStract}

This study uses a business network perspective to investigate the industry 4.0 context with the internet of things (IoT) as its enabling technology and product-use data as its core network resource. A three-stage qualitative methodology (interviews, focus group, delphibased inquiry) was used to examine the case of an emergent IoT-based business network in the UK road transport industry to examine: i) how aspects of product use data influence the benefit opportunities the data provide to the different network actors; ii) how the capturing of the benefit opportunities in a network context is impacted by key barriers; and iii) how network capabilities can overcome these barriers to capture benefits from product-use data. The study thereby contributes to an understanding of the industry 4.0 context from a resource dependency theory perspective and provides concrete recommendations for management operating in this context.

Keywords - Industry 4.0, industrial internet, internet of things, IoT, business network, resource dependence.

This work was supported by the Economic and Social Research Council (ESRC) under Grant Ref ES/P010148/1 'Pathways towards Servitization: A trans-national study of Organisational Transformation. 


\title{
Capturing the Benefits of Industry 4.0: A Business Network Perspective
}

Andreas Schroeder

Aston University, Birmingham, UK

a.schroeder@aston.ac.uk

\author{
Ali Z. Bigdeli \\ Aston University, Birmingham, UK \\ Carlos Galera Zarcos \\ Coventry University, Coventry, UK
}

\section{Tim Baines}

Aston University, Birmingham, UK

\begin{abstract}
This study uses a business network perspective to investigate the industry 4.0 context with the internet of things (IoT) as its enabling technology and product-use data as its core network resource. A three-stage qualitative methodology (interviews, focus group, delphibased inquiry) was used to examine the case of an emergent IoT-based business network in the UK road transport industry to examine: i) how aspects of product use data influence the benefit opportunities the data provide to the different network actors; ii) how the capturing of the benefit opportunities in a network context is impacted by key barriers; and iii) how network capabilities can overcome these barriers to capture benefits from product-use data. The study thereby contributes to an understanding of the industry 4.0 context from a resource dependency theory perspective and provides concrete recommendations for management operating in this context.
\end{abstract}

Keywords - Industry 4.0, industrial internet, internet of things, IoT, business network, resource dependence.

Paper type - Research paper.

\section{Introduction}

The widespread digitalisation in industrial and manufacturing contexts brought about by the development and spread of the industry 4.0 context and the Internet of Things (IoT) as its 
enabling technology is generating substantial opportunities for innovation and value creation (e.g. McKinsey Global Institute 2015; Fatorachian and Kazemi 2018). Digitalisation implies an extensive reconfiguration of everyday products in terms of new communication, programmability and traceability properties that extend the products' scope and function (Whitmore, Agarwal, and $\mathrm{Da} \mathrm{Xu}$ 2015). Integrating these digitalised products into an IoT technology platform enables their seamless communication with each other and their various stakeholders, who utilise these new properties for unbound distributed innovation (Yoo, Henfridsson, and Lyytinen 2010) and the development of novel business opportunities (Lyytinen, Yoo, and Boland Jr 2016). With the digitalisation of products and the integration of them into an IoT technology platform gathering momentum, it is becoming important to create the required organisational environment and innovative approaches to foster the distributed creative potential and capture the business opportunities the industry 4.0 context offers.

The critical resource underlying the innovation potential and business opportunities is the 'product-use data' which the digitalised product creates in an industry 4.0 context. Productuse data captures and communicates (often in 'near real time') detailed insights into the product's status and operations (Porter and Heppelmann 2014). This data not only creates opportunities for product users to remotely monitor their products and assess their performance but also for product manufacturers and third parties (Grubic 2014).

Continuous access to product-use data enables manufacturers to understand how their products are being used and how their use impacts operation and product performance (Nadj et al. 2016; Coreynen, Matthyssens, and Van Bockhaven 2016). These insights even enable manufacturers to expand from traditional (transactional product-sale) to servitized business models, where the manufacturer monitors the product on behalf of the customer and retains responsibility for product performance (Baines and Lightfoot 2013). Third parties may further integrate the product-use data with additional data sources to identify optimisation opportunities of complex manufacturing operations involving multiple products (Porter and Heppelmann 2014). In an industry 4.0 context, product-use data is a core resource which provides multiple stakeholders with a diverse range of benefit opportunities.

The multi-stakeholder dependence on product-use data creates substantial theoretical and practical business challenges. It creates considerable risks for manufacturers and third-party providers which may not have control over these critical external resources. Resource 
dependency theory (RDT) suggests that firms will seek to maximise their autonomy from exchange partners holding critical resources or minimise uncertainty with regards to these resources (Davis and Adam Cobb 2010). Firms have a specific repertoire of tactics available to internalise or tightly control these critical resources and thereby reduce their external dependencies (Hillman, Withers, and Collins 2009).

However, the conceptualisation of product-use data as a critical resource to some extent challenges the assumptions of RDT: for manufacturers and third parties to have a high resource value, the product-use data needs to be drawn from externally-used products, capturing a large diversity of use-scenarios; also for product users, the resource value of data capturing the status and operation of their own products is significantly enhanced when integrated with data from other products that are used in similar or dissimilar scenarios (e.g. benchmarking). Despite their dependence on product-use data, it seems that various stakeholders in an industry 4.0 context benefit from defying the RDT-based assumptions and not internalising or centrally controlling the resource creation or access (Agrifoglio et al. 2017).

To explore the particular role and theoretical implications of product-use data, the present study conceptualises the multi-stakeholder industry 4.0 context as an emergent business network with product-use data as its shared network resource. A business network describes a group of interdependent organisations which are linked to each other through nonhierarchical 'weakly manageable' relationships (Anderson, Håkansson, and Johanson 1994, 2; Möller and Rajala 2007). We will use a business network perspective in the present study as an investigative framework to characterise the industry 4.0 context and examine its firm-, relational- and network-level implications (Ramos et al. 2013; Snehota and Hakansson 1995). By drawing on the network resource notion, the study conceptualises product-use data as resource which, although embedded in its network, can alter a firm's opportunity sets and strategic behaviours (Lavie 2006; Gulati and Sytch 2007). The business network perspective and the network resource notion provides a helpful conceptual basis for exploring the range of benefit opportunities network actors can derive from the product-use data, the barriers that limit the benefit capture and the capabilities required for overcoming these.

The study examines the case of an emergent business network within the UK road-transport industry using a three-stage research process. The study first collects and analyses interview data to identify how the network actors can derive benefit opportunities from product-use 
data. In the second stage, the study uses a focus group of a diverse range of network actors to examine how the capturing of the benefit opportunities in a network context is impacted by key barriers. In the third stage, the study draws on a Delphi panel to identify the concrete capabilities required for overcoming the benefit capture barriers.

The findings identify a range of benefit opportunities the different network actors can derive from product-use data but also identify several cultural, standards-, value- and resource-based barriers that limit the network actors' ability to capture these benefit opportunities. Several concrete recommendations for overcoming these barriers are developed in the third research stage to help firms within the network not only with the creation and sharing of product-use data but also with the creation and sharing of benefits within the network.

The study and its findings contribute to the development of a business network perspective on the industry 4.0 context which illustrates the multiple levels of interaction and dependencies that characterise this context. The study also challenges and extends existing resource theory (i.e. RDT, RBV) by contributing to an understanding of the specific resource aspects of product-use data and their implications. Further, the study helps to advance the understanding of the network capability notion and its applicability in the industry 4.0 context.

Following this introduction, a focused review of the business network literature, its resource dependence and capability implications is provided and the current research on industry 4.0, product digitalisation and the IoT technology platform is outlined. Then, the specific roadtransport industry case is described and the study's three-step research methodology is explained. The paper concludes by presenting the research findings and discussing their implications for theory and industrial practice.

\section{Theoretical background: IoT business networks, network resources and capabilities}

\section{A business network perspective on IoT}

The wider literature defines a business network as a "set of two or more connected business relationships, in which each exchange relation is between business firms that are conceptualised as collective actors" (Anderson, Håkansson, and Johanson 1994, 2).

'Connected relationships' implies that the firms' exchanges are contingent on exchanges with 
other firms (Johanson and Vahlne 2011). Business network conceptualisations commonly emphasise the non-hierarchical nature of these inter-firm relationships (Provan, Fish, and Sydow 2007; Jagdev and Thoben 2001), which render business networks 'weakly manageable' (Möller and Rajala 2007). Instead, one of the core mechanisms that governs the complex interactions between actors in business networks is resource ties (Snehota and Hakansson 1995), which describes the access or transfer of resources (e.g. financial, material, technological) between network actors (Olkkonen 2001). Other governance mechanisms considered are, activity links (members' operational connections and mutual adaptations), and actor bonds (members' relationships and mutual perceptions) (Snehota and Hakansson 1995). Because they emphasise firm interdependencies as determinants for firm behaviour, business network research approaches are often considered alternatives to marketbased research approaches to explain firm behaviour (Möller 2013).

Despite the substantial body of literature relating to the topic, business network research represents a research perspective rather than a theory in its own right (Möller 2013; Jagdev and Thoben 2001). Adopting a business network perspective commonly implies that a study seeks to analyse and understand a phenomenon across three closely interconnected levels of analysis (Ramos et al. 2013; Snehota and Hakansson 1995): the firm level, the relational level and the network level. All three levels of analysis are understood to influence one another through interaction and interdependent coevolution (Welch and Wilkinson 2002). Together they provide a framework to identify a 'shared network view' as the collective understanding different network actors hold on a particular topic (Henneberg, Naudé, and Mouzas 2010).

The present paper focuses on the specific phenomenon of an emergent business network. Emergent business networks develop organically from repeated interactions between firms (Raab and Kenis 2009) and so contrast with formally designed business networks where clear leadership roles and responsibilities are established (as in R\&D consortiums, Inkpen and Tsang 2005). Although general network attributes are shared (e.g. non-hierarchical, simultaneous competition and collaboration), emergent business networks often denote ambiguities of the networks' boundaries, the networks' membership, and the members' roles and relationships (Inkpen and Tsang 2005). Emergent networks, in particular, face the challenges of establishing their collective identity (Raab and Kenis 2009), developing network objectives (D'Aunno and Zuckerman 1987), and maintaining effective interactions among an often highly diverse membership (Möller and Svahn 2009). Trust, at an 
interorganisational and interpersonal level, represents a key enabler of emergent networks as it creates a critical safeguard against opportunism (Claro et al. 2003, Gadde et al. 2003).

\section{IoT context as business networks}

One of the core technologies underlying the industry 4.0 context is the internet of things (IoT) (Fatorachian and Kazemi 2018). The IoT describes "a paradigm where everyday [products] can be equipped with identifying, sensing, networking and processing capabilities that will allow them to communicate with one another and with other devices and services over the Internet" (Whitmore, Agarwal, and Da Xu 2015, 261).

It implies an integration of sophisticated software components into the product, not only to operate its physical components (operational technology, OT) but also to pre-processes and communicate the product-use data (information technology, IT) (Lin et al. 2015). The software components enable a seamless, continuous, and ubiquitous communication among connected products (Bello and Zeadally 2016) and also enable manufacturers to remotely and continuously update their products (Sinclair, 2017), a feature that was previously limited to 'software-only' products. Yet, the continuous connectivity and convergence between OT and IT also incorporates the cyber-security concerns from the digital domain to the core operations of physical products (Rayes and Salam 2017).

The connectivity and continuous communication of the products stimulates the emergence of business networks (Laya, Markendahl, and Lundberg 2018). The product's connectivity enables a continuous internet-based link between the Internet, the product and by extension, the product user (Andersson and Mattsson 2015). In the industrial context, the IoT (via the product) establishes ongoing network relationships among product users, product manufacturers and third-parties (Porter and Heppelmann 2014). However, in the absence of formal leadership structures and clearly allocated responsibilities among the actors, the business relationships might only take the form of an emerging business network (Inkpen and Tsang 2005).

Illustrations of the benefit opportunities the IoT-based connectivity provides to the different network actors in an industrial context are emerging in the literature (Agrifoglio et al. 2017). For the manufacturer, retaining connectivity with a product beyond the factory gate provides ongoing product-use data access or even the ability to continuously interact with the product (through actuators) (Porter and Heppelmann 2014; Schroeder and Kotlarsky 2015; Pagani 
and Pardo 2017). Manufacturers can obtain detailed insights on how their products are used (to identify new product requirements), how their products perform in different use scenarios (to identify quality issues), or what additional value propositions can be provided to their customers (to attract new business) (Nadj et al. 2016; Coreynen, Matthyssens, and Van Bockhaven 2016; Fatorachian and Kazemi 2018; Agrifoglio et al. 2017).

The additional data-based insights provide manufacturers with the opportunity to develop new pay-per-use, outcome-based or other subscription-based business models (Baines et al. 2017; Kowalkowski et al. 2017). The increased visibility the product-use data affords helps manufacturers to manage the risks that are inherent to these business models. Industrial users of IoT-enabled products can employ detailed product-use data to identify product utilisation patterns, opportunities for efficiency gains and process improvement.

The IoT-based connectivity further provides product users with the ability to remotely monitor and control their products (performance visibility, operations efficiency) (Sinclair 2017), or integrate and jointly coordinate several products (to create product systems) (Porter and Heppelmann 2014). The literature also describes how users who provide the manufacturers with appropriate product-use data access can benefit from faster or more costefficient support from the manufacturer, minimised product downtime (through predictive maintenance) and the ability to seamlessly draw upon manufacturers' expertise (to gain remote diagnostics and support) (Sinclair 2017; Grubic 2014; Kindström and Kowalkowski 2014; Opresnik and Taisch 2015; Coreynen, Matthyssens, and Van Bockhaven 2016).

\section{Product-use data}

The above review points to product-use data as the core resource that underlies the benefit opportunities the industry 4.0 business network provides to its member-firms. Its central role in an industry 4.0 context has already been identified by several authors with some labelling it as a 'resource' (but without conceptualising it explicitly) (Foulonneau et al. 2014; Hartmann et al. 2016; Kambatla et al. 2014; Rymaszewska, Helo, and Gunasekaran 2017).

Resources form a particular focal point of business network research. Bae and Gargiulo (2004) argue that the firm's search for resources is a driver of business network formation. Resource Dependency Theory (RDT) (Pfeffer and Salancik 2003) correspondingly has emerged as one theoretical basis for business network research (Möller 2013) and has shaped the consideration of resources in a business network context. RDT deals with a firm's 
dependence on another firm's resources and the consequences and strategies for managing this dependence (Toms and Filatotchev 2004). The focus on external resources (e.g. production facilities, trade secrets, engineering experience) differentiates it from the resourcebased view, which deals with a firm's internal resources and their contribution (Barney 1991; Peteraf 1993). Strategies RDT studies commonly consider for firms to manage and potentially minimise their external dependencies include: i) restructuring operations (to reduce resource dependence); ii) cultivating alternative sources of supply; iii) forming longterm contracts, joint ventures or even mergers (to obtain direct resource control) (Hillman, Withers, and Collins 2009).

Business networks expand the nature of the dependence considered in RDT applications from a firm-level to a multi-organisational context. Such RDT applications specifically recognise the notion of 'mutual dependence' (two firms having resources that the other needs) (Gulati and Sytch 2007) emphasising that resource dependence is often not a zero-sum game (Hillman, Withers, and Collins 2009). Business network-focused RDT applications also explore 'resource co-creation' scenarios, which consider firm's relationships as loci for resource creation, instead of being only loci for resource access or exchange (Möller 2013).

RDT applications in business network also expand the repertoire of strategies employed to manage the complex resource interdependence. Network actors manage the access to valued resources by socialising or through the exchange of other valuable goods, such as status, friendship, or information (Casciaro and Piskorski 2005; Blankenburg Holm, Eriksson, and Johanson 1999). While firm-level RDT applications focus on strategic, economic or structural strategies to manage resource access, business network-focused RDT applications also emphasise the socially embedded context of firms (Hillman, Withers, and Collins 2009).

\section{Product-use data as network resource}

A systematic conceptualisation of product-use data as resource is required to understand its role in an industry 4.0 business network context. The wider business literature does not generally consider data as a 'strategic resource' (Wade and Hulland 2004; Otto 2015; Roden et al. 2017) and instead focuses on knowledge, relationships and the IT infrastructure as a strategic resource (e.g. Karimi, Somers, and Bhattacherjee 2007; Chang and Wang 2011). More specifically, studies drawing on the established VRIN framework (Barney 1991) to characterise resources argue that data is 'not rare' and instead point to intangible data-related skills as the strategic resource of interest (Braganza et al. 2017; Gupta and George 2016). 
The recent attention to Big Data Analytics and the IoT, however, clearly highlights the importance and strategic value of data. In addition to enabling new business models (described above) product-use data can even realign the manufacturer's value chains as its dependencies and negotiation power is affected by data access, ownership and analytical capabilities (Porter and Heppelman 2014). Industry concerns over 'digital lock-in' scenarios related to data-based dependencies or proprietary standards have already been documented (Brewster et al. 2017). Yet, a systematic theorisation that reconsiders the role of data as 'strategic resource' is still outstanding (Roden et al. 2017).

Nason and Wiklund's (2015) notion of resource fungibility helps to further characterise the resource status of product-use data by considering the benefit opportunities it creates. On the one hand, product-use data exhibits low external fungibility, as it is highly specific in its scope (the insights that can be derived are tightly linked to a specific product or use-scenario, compared with the generic benefit opportunities of other resources (e.g. money). On the other hand, product-use data exhibits high internal fungibility, as it is highly versatile in its optionality (a variety of current and potential future analytical and operational scenarios utilise the same data in different ways: e.g. predictive analytics for manufacturers and product efficiency information for the customer). Dierickx and Cool (1989) explicitly consider those resources that exhibit low external and high internal fungibility as sources of competitive advantage.

Lavie's (2006) focus on the resource locus further helps to characterise product-use data as a network resource ("external resources embedded in the firm's alliance network that provide strategic opportunities and affect firm behavior and value" (p. 638)). Network resources turn the focus from 'resource ownership' to 'resource access', as firms can extract value from resources they do not fully own or control, which can significantly alter a firm's opportunity set and strategic behaviour (Gulati and Sytch 2007; Wassmer and Dussauge 2011). Lavie (2006) also points out that in business networks with high actor interdependency, a focus on resource access is not enough, as access to the benefit opportunities that can be derived is also critical (resource-based rents).

Product-use data within an industry 4.0 business network represents a specific network resource scenario of which we know very little. It's low external and high internal fungibility suggests that product-use data represents a source of competitive advantage for different network actors. Despite product-use data's particular importance, there is still a substantial 
gap in our understanding of the specific aspects of this resource that play a role in creating benefit opportunities in a network context. To address this gap and to start developing an understanding of product-use data as a network resource, the following research question was developed:

RQ1: How do aspects of the product use data resource influence the benefit opportunities the data provide to the different network actors?

\section{Barriers to product-use data benefit capture}

A critical area of business network research is the identification of barriers that stand in the way of actors capturing the benefit opportunities the network offers. McGrath and O'Toole (2010), for example, examine how a reduced ability among SME's to visualise their interorganisational relationships creates a barrier to exploiting the shared marketing opportunities that the network offers. Öberg and Shih (2014) examine how diverging innovation interests and interaction goals can become a major innovation barrier within pharma networks.

To understand the barriers that stand in the way of firms capturing the benefits of product-use data, it is important to consider its properties as a digital artefact (Kallinikos, Aaltonen, and Marton 2013). Product-use data is in a perpetual state of incompleteness: unlike a physical artefact which is developed as a finite application, product-use data continuously develops without excluding any tasks it will use for nor the range of actors that will be using it (or it may remain 'data exhaust', Gupta and George 2016). Further, product-use data is only meaningful in context: deriving relevant insights from performance data, for example, requires insights on the way performance is being measured and the task the product is carrying out. Further, product-use data is editable, interactive and distributed: it can be transformed (and can co-exist) in different formats and different levels of granularity.

Positioning product-use data as a specific network resource in the industry 4.0 context requires an understanding of the barriers that stand in the way of network actors capturing its benefit opportunities. Unlike other network resources (e.g. relationships, capabilities) product-use data represents a resource in its raw form, requiring significant transformation and processing efforts to capture its benefit opportunities (King, Grover, and Hufnagel 1989; Wang et al. 2018). Such a drawn out 'data-to-value chain' (Crié and Micheaux 2006) entails various intermediate steps that are of importance in understanding the barriers to capturing 
the benefits from product-use data in an IoT enabled network context. To identify the range of barriers and their impacts, the following research question was developed:

RQ2: How do key barriers impact on the network actor's ability to capture the benefit opportunities of product-use data in an industry 4.0 context?

\section{Developing network capabilities}

Explorations of 'network capabilities' constitute another important research angle to understand business networks and their underlying dynamics (Möller and Halinen 2017; Möller, Rajala, and Svahn 2005; Äyväri and Möller 2008). From a business network perspective, capabilities represent a multi-level concept capturing the firm-level, relationallevel and network-level competences required to support a network actor's benefit opportunity capture. Firm level network capabilities identify a network actor's ability to effectively utilise the business network (Walter, Auer, and Ritter 2006). Research explores the exchange, coordination, and adaptation activities that enable firms to build, handle, and exploit their business networks (Vesalainen and Hakala 2014). Relational-level network capabilities identify practices that help network actors to form the valuable relationships required for benefit capture. Specific studies highlight coordination practices (Kogut 2000), mutual adaptations (Fang, Palmatier, and Evans 2008; Palmatier, Dant, and Grewal 2007) or the reciprocal influencing of the actor's innovation behaviour (Kohtamäki, Rabetino, and Möller 2017). Network level capabilities capture the network's overall ability to create supportive environment for its members (Möller and Svahn 2003). This includes the network's ability to facilitate learning and joint gains or the processes for producing and sharing collective innovations (Kogut 2000).

Research, at this point, is only starting to explore the particular IoT network-related capabilities (McKelvey, Tanriverdi, and Yoo 2016). Studies are actively exploring firm-level technical capabilities actors require to effectively process the product-use data (e.g. Kuo and Kusiak 2018fc; Wang et al. 2018). This technology-dominated approach to capabilities has already been criticised by Venkatraman et al. (2014), who specifically call for investigations of the operational, dynamic, and improvisational capabilities firms require to effectively exploit their IoT enabled network context. A focus on network capabilities in an industry 4.0 context not only expands beyond the technology focus but also expands beyond the firmlevel focus to understand the capabilities that are required within the network to allow for the 
benefit opportunities to be captured. To create the required understanding of the network capabilities required, the following research question has been formulated:

RQ3: How can network capabilities overcome the barriers to capturing benefits from product-use data?

\section{The research}

The adoption of a business network perspective provides an opportunity to establish a 'shared network view' (Henneberg, Naudé, and Mouzas 2010) on the product-use data's resource aspects, benefit capture barriers and network capabilities that are important in an IoT enabled network context. Establishing a 'shared network view' requires the elicitation and integrating of the dispersed cognitive pictures held by individuals participating in the emergent business network (Henneberg, Mouzas, and Naudé 2006; Ford et al. 2003). To allow for the close iterative interactions with the network members required for the development of a shared network view, business network investigations often focus on single cases (Halinen and Törnroos 2005; Olkkonen 2001; Salmi 2000; Henneberg, Mouzas, and Naudé 2006; Ford et al. 2003).

The present study draws on the case of an emergent business network within the UK road transport industry. The primary source of product-use data within road transport is the IoTenabled truck. Numerous sensors, data collection and processing devices capture and communicate (via cellular networks) product-use data detailing aspects of the truck's performance (e.g. fuel consumption, oil pressure) operation (e.g. revolutions per minute, seatbelt use, engine idling, cruise-control utilisation) or components (e.g. tyre pressure, tyre temperature) (Watson et al. 2010; Dalsace, Ulaga, and Renault 2012). The extent of productuse data modern trucks create, process and communicate far exceeds the capabilities of traditional telematics systems, which focus on location-related data (Vaia et al. 2012). By $2016,30 \%$ of UK road transport operators had adopted such IoT-enabled trucks into their fleets (Cole 2016).

As firms are often part of various overlapping business networks (e.g. operational or R\&D networks) (Landqvist and Lind 2018fc), identifying and isolating the particular 'focal network' of interest is critical (Halinen and Törnroos 2005). This is especially so in emergent business networks where membership is largely informal and network boundaries are fluid (Raab and Kenis 2009). The focal road transport network investigated spans two original 
equipment manufacturers (OEM), five transport operators (TO), and two service providers (details are provided below in Table 1). The firms were selected for their dependence on product-use data as a core resource.

The TOs in the network acquire trucks through a mixture of (1) purchase or (2) service contracts (from different OEMs) or (3) rental (from different fleet management providers) which determines the data sharing and ownership arrangements. Figure 1 illustrates how product-use data (e.g. truck performance and operation) is collected and processed by a digital service provider (DSP) which distributes the data and analytics (in different levels of aggregation) to OEMs, TOs or fleet management providers. For purchased trucks, TOs choose their own digital service provider; for trucks or components under service contract, TOs are dependent on the OEM's choice of DSP; for rented trucks, TOs are dependent on the fleet management provider's choice of DSP. TOs, OEMs, DSPs and fleet management providers also work with other partners and are part of other networks (as indicated by the dotted squares) which are outside the scope of the present research.

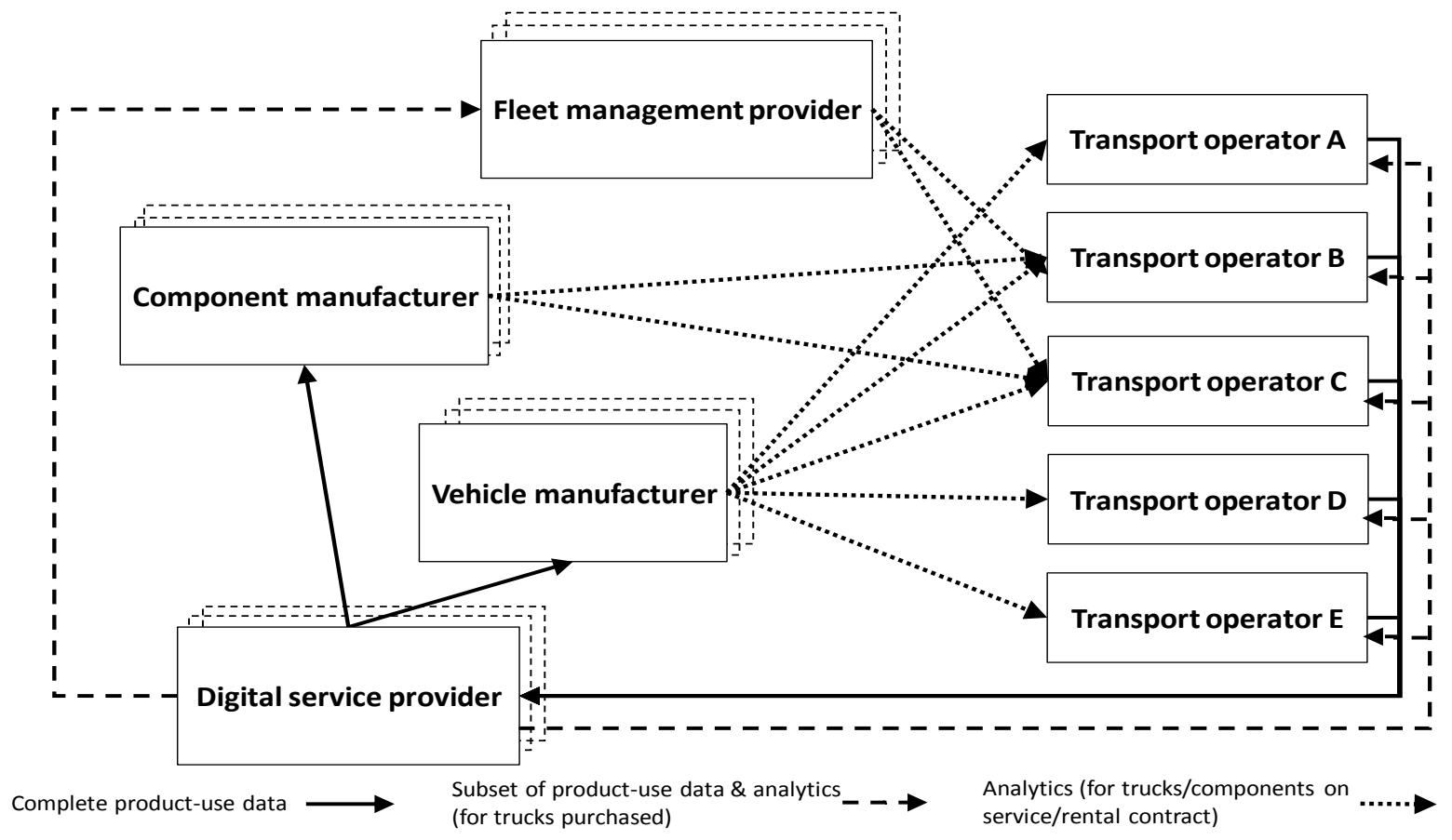

Figure 1. Flow of product-use data in analysed business network 


\section{Research methodology}

A qualitative research method rooted in a 'moderate constructionist' perspective was used to guide the research (Van Den Belt 2003). The objective of a moderate constructionist perspective in the context of a single case is to identify the "local, community-bounded, interacting forms of truth that are created and validated through dialogue in different communities" (Järvensivu and Törnroos 2010, 101). A three-stage qualitative method was adopted to elicit these community insights:

- Stage One: individual interviews and thematic analysis to identify the product-use data's benefit opportunities and important resource aspects;

- Stage Two: a focus group interview to identify the shared network view on the barriers to capturing the benefit opportunities;

- Stage Three: a Delphi-based approach to identify the shared network view on the network capabilities required to overcome the barriers to benefit capture.

\section{Stage One: individual interviews and thematic analysis}

To address the objectives of the first stage, individual interviews were conducted and analysed to obtain valid insider perspectives from representatives of core network-actors (Järvensivu and Törnroos 2010). The interviews involved seven senior managers from vehicle manufacturers, component manufacturers, digital service providers, and transport operators (see Table 1). They lasted between 20 and 40 minutes each and followed a semistructured format with questions focusing on: i) the benefit opportunities that product-use data provides and ii) the data characteristics that are important for achieving these benefits. Participants outlined a variety of scenarios explaining how product-use data supports particular aspects of their business model and specifying the nature of the contributions (e.g. cost-advantages, responsiveness). Probing questions further explored the particular data characteristics required to benefit from its contributions.

The analysis of the interview data began with the development of short vignettes ${ }^{1}$. A vignette represents a preliminary research step which pulls together "rich 'pockets' of especially representative, meaningful data [...] in a focused way for interim understanding" (Miles and Huberman 1994, 81). Hence, vignettes were created to provide structured presentations of the

\footnotetext{
${ }^{1}$ The term 'vignettes' here describes an analytical step, not a technique for illustrating particular perspectives to the reader.
} 
business models, product-use data characteristics and contributions encountered in each participant's interview data. The vignettes formed the basis for the subsequent joint iterative thematic analysis process by providing the research team with a shared understanding of the encountered scenarios.

\begin{tabular}{|l|l|l|l|l|l|}
\hline \multicolumn{2}{|c|}{ Job Title of Participant } & \multicolumn{1}{|c|}{ Type of Firm } & Stage 1 & Stage 2 & Stage 3 \\
\hline 1 & Managing Director & Digital service provider & X & X & \\
\hline 2 & Vice President & Digital service provider & X & X & \\
\hline 3 & Account Manager & Digital service provider & & X & X \\
\hline 4 & Channel Director & Digital service provider & & X & \\
\hline 5 & $\begin{array}{l}\text { Business Development } \\
\text { Manager }\end{array}$ & $\begin{array}{l}\text { Fleet management } \\
\text { services }\end{array}$ & & X & \\
\hline 6 & $\begin{array}{l}\text { Business Development } \\
\text { Executive }\end{array}$ & $\begin{array}{l}\text { Fleet management } \\
\text { services }\end{array}$ & & $\mathrm{X}$ & \\
\hline 7 & Fleet Manager & Transport operator A & & X & \\
\hline 8 & Fleet Manager & Transport operator B & & $\mathrm{X}$ & \\
\hline 9 & $\begin{array}{l}\text { Director }- \text { Technical } \\
\text { Services }\end{array}$ & Transport operator C & & $\mathrm{X}$ & $\mathrm{X}$ \\
\hline 10 & Owner-Manager & Transport operator D & $\mathrm{X}$ & & \\
\hline 11 & Director & Transport operator E & $\mathrm{X}$ & $\mathrm{X}$ & $\mathrm{X}$ \\
\hline 12 & Director - Aftersales & Vehicle manufacturer & & $\mathrm{X}$ & \\
\hline 13 & $\begin{array}{l}\text { Director }- \text { Telematics } \\
\text { Services }\end{array}$ & Vehicle manufacturer & & $\mathrm{X}$ & \\
\hline 14 & Chief Executive Officer & Vehicle manufacturer & $\mathrm{X}$ & $\mathrm{X}$ & $\mathrm{X}$ \\
\hline 15 & Retail Director & Vehicle manufacturer & & & $\mathrm{X}$ \\
\hline 16 & Dealer Principal & Vehicle manufacturer & $\mathrm{X}$ & & $\mathrm{X}$ \\
\hline 17 & $\begin{array}{l}\text { Director }- \text { Service } \\
\text { Management }\end{array}$ & Vehicle manufacturer & & & $\mathrm{X}$ \\
\hline 18 & Chief Innovation Officer & Component manufacturer & & $\mathrm{X}$ & \\
\hline 19 & Commercial Director & Component manufacturer & & $\mathrm{X}$ & \\
\hline 20 & Innovation Manager & Component manufacturer & & $\mathrm{X}$ & \\
\hline 21 & $\begin{array}{l}\text { Services Innovation } \\
\text { Manager }\end{array}$ & Component manufacturer & $\mathrm{X}$ & $\mathrm{X}$ & \\
\hline
\end{tabular}

Table 1: List of participants

The objective of the iterative thematic analysis process (Braun and Clarke 2006) was to differentiate the benefit capture scenarios collated in the vignettes and identify the range of relevant product-use data characteristics. The involvement of the wider research team in the thematic analysis process ensured that a range of expertise could be drawn upon to help specify the stakeholder perspectives and devise categories that are coherent across the diverse stakeholder groups represented by the network actors (see Stage One findings in Section 4). 


\section{Stage Two: identifying and prioritising the main barriers}

The second research stage sought to identify a shared network view on the barriers to capturing the product-use data's benefit opportunities. A focus group was identified as a platform for discussion and integration (Sutton and Arnold 2013) to elicit participants' cognitive pictures on the barriers to benefit capture (Henneberg, Mouzas, and Naudé 2006) and subsequently integrate these to establish a shared network view (Matthyssens, Vandenbempt, and Weyns 2009).

Recommendations regarding the ideal number of participants in a focus group differ widely (Fern 1982) ${ }^{2}$. Smaller groups are preferred for emotionally charged topics while larger groups allow for a greater number of potential responses and perspectives, and are deemed appropriate in the case of discovering information on neutral topics (Morgan 1996). The focus group set up for this research stage involved 17 senior managers representing eight interdependent network actors (see Table 1). The opportunity to draw on the diverse perspectives and stimulate the development of a shared network view among these network actors was considered a rare research opportunity ${ }^{3}$ which justified the group size. Facilitation techniques (Gibbs 1997) applied in the focus group session ensured that the contributions of participants were balanced and that the effects of the group size were limited.

A structured three-step process was followed to first elicit the participants' cognitive pictures of the barriers to benefit capture and then establish a shared network view:

1) Participants identified factors limiting their firm's ability to utilise the benefit opportunities of product-use data. Each factor identified was noted on a separate card to create a permanent record of the participant's examples of barriers to benefit capture and was explained to the other participants; a total of 68 cards representing the individual perspectives of the participants were created and displayed.

2) Participants iteratively consolidated the cards into related examples and grouped these into themes representing the overarching barriers identified. A total of ten themes emerged through this participant interaction, representing the group's consolidated and shared view on the overarching barriers to benefit capture.

\footnotetext{
${ }^{2}$ Fern (1982) in his review found that focus group sizes are commonly ranging from 5-20 members.

${ }^{3}$ Previous dealings among these network members had been limited to pairwise interactions.
} 
3) Participants ranked these overarching barriers according to their relative importance, creating a comprehensive network view which pinpointed and prioritised the barriers to benefit capture; they then reflected on the barriers identified and provided background information regarding how the themes manifest themselves within the network.

The focus group session lasted for four hours and was moderated by a senior academic with facilitation experience to ensure high levels of involvement despite the large number of participants. A further four academics assumed supporting roles, taking notes on the arguments underlying the barriers and their individual firm-, relational- and network-level manifestations. Subsequent analysis focused on interpreting the barriers through the lens of a business network perspective. The research team used their field notes to interpret the barriers and their manifestations within the business network perspectives' levels of analysis and to identify the nature of the impact on the capturing of the benefit opportunities (see findings presented in Section 4.2).

\section{Stage Three: developing recommendations}

The third stage sought to identify the network capabilities required for overcoming the barriers to capturing the benefit opportunities. A Delphi-based method was identified as a suitable group mechanism for eliciting and consolidating real-world expertise on complex problems and future events ('what could/should be') (Hsu and Sandford 2007). Although studies diverge in their Delphi-method application (Donohoe and Needham 2009), guidelines highlight the importance of developing a panel of subject-matter experts who have a stake in the study's outcome and would, therefore, campaign for their views to be represented (Hsu and Sandford 2007). For the present study, a panel of seven senior experts was drawn from the focal network (see Table 1) - seven being an appropriate number to create a meaningful diversity of views (Donohoe and Needham 2009).

Via email, the panel members received a summary of the prioritised benefit capture barriers previously identified, together with a request to provide concrete recommendations on the steps and initiatives required to overcome these barriers. The research team synthesised the diverse responses with a focus on integrating the contributions and aptly representing the recommendations provided. The researchers then redistributed the synthesised responses to provide the panel members with an opportunity to review and comment on the recommendations, which led to two additional contributions (for clarification purposes). Although originally a third round of interaction had been envisaged, the process was 
concluded after this second round (following Donohoe and Needham 2009), as none of the panel members further challenged the synthesised recommendations (the findings are presented in Section 4.3)

\section{Research findings}

\section{Stage One findings: benefit opportunities and resource aspects}

The analysis of the vignettes provided important insights into the range of benefit opportunities product-use data (i.e. truck performance and operation data) provide to the IoT network actors and how these benefit opportunities are impacted by particular aspects of the data resource.

The analysis showed the benefit opportunities that transport operators derive from productuse data. They were found to depend on product-use data to create critical operational transparency helping to understand their costs and identify operational inefficiencies. Transport operators emphasised how detailed performance and operational insights provide the critical basis for managing their drivers and incentivising specific driver behaviour (e.g. fuel-efficient driving), thereby enhancing their operational effectiveness. Transport operators also use detailed performance and operational insights to create compliance efficiency by demonstrating operational excellence to authorities and insurance providers (contributing to insurance premium deductions and a trust scheme for inspection).

The analysis has further shown how the product-use data provides the basis for a variety of benefit opportunities for the manufacturer. The manufacturers were found to utilise the detailed performance and operational insights to create operational transparency of their products (particularly important where products are provided through a full-service contract and manufacturers retain uptime responsibility). The manufacturers were also found to utilise the product-use data to obtain R\&D insights (e.g. vehicle and component performance), as illustrated by one of the representatives:

[The trucks] are a mobile research and development area, we're getting real $R \& D$ information that's fed back then to production, to engineering, to suppliers, so it leads to reduced [risk and cost].

(Chief Executive Officer, Vehicle Manufacturer) 
Manufacturers also used the data for customer profiling and to provide their customers with targeted operational improvement advice contributing to service development and delivery. The data was also used for risk management purposes, allowing the manufacturer to better manage warranty claims and understand the product's residual value (where trucks are provided through a full-service contract and the manufacturer retains ownership).

For the digital service provider, the product-use data not only constitutes the basis of its business (i.e. collection and processing data), but also provides the basis for the continuous innovation and refinement of the analytical processes to create the underlying insights:

\begin{abstract}
[Manufacturers] will never succeed in this, because it takes them seven years to build a product ... operators, if they want a change of data or if they want more of this or less of that, they want it now, they're not prepared to wait seven days, seven weeks, seven months, which is what it would take an OEM to bring about a change ... [We] will bring about a change in weeks or months that it would take the OEM years, and that's the difference, the speed of reaction.
\end{abstract}

\title{
(Managing Director, Digital Service Provider)
}

On this basis, the digital service provider also uses the performance and operational insights to create entirely new value propositions such as the scheduling and routing optimisation services.

\section{Product-use data resource aspects}

The analysis further focused on identifying the resource attributes of the product-use data that play an important part in the creation of these diverse benefit opportunities.

The descriptions of the benefit opportunities consistently emphasised the importance of access as a critical resource aspect of product-use data. Although considerations of data access are already recognised as critical in the IoT literature (e.g. Marjani et al. 2017), the analysis highlighted specific forms of access that play an important role in the benefit capture scenarios. In particular, the distinction between access to raw data and access to processed data was described as an important differentiation. Transport operators, for example, do not automatically obtain access to the raw data from engine and internal systems, as the vehicle manufacturer claims IP rights on these. Having to rely on pre-processed data already limits 
transport operator's own analytical flexibility. Yet transport operators also emphasised how their access to processed data also creates important benefit opportunities. It allows the operator to tap into the analytical capabilities of other network actors to obtain complex insights, such as critical driver behaviour analytics, which are based on large comparative datasets.

A further facet of data access that emerged from the analysis of the benefit capture scenario descriptions points to the differentiation between core product-use data and peripheral data. For the manufacturer and digital service provider, the access to the transport operator's peripheral data (e.g. trailer details, load specifications) complements the product-use data and helps to refine the performance and operational insights.

Also of interest for the creation of benefit opportunities (especially for the transport operator) were the measurement parameters, data format and reliability of the product-use data. As transport operators generally seek to hold a variety of truck makes and models (to minimise product risks) they are exposed to the manufacturers' use of different standards to measure their parameters of interest (e.g. driver harsh cornering) or using different data formats, as coherent fleet-level analysis requires significant consolidation efforts. Transport operators also highlighted the importance data reliability has for them; by using the product-use data to incentivise driver behaviour, any inaccuracies and the subsequent loss of confidence have a detrimental effect on its utility in this regard.

The analysis of the interview data provided important insights into the range of benefit opportunities product-use data provides to the network actors and the important resource aspects that play a role in the creation of these benefit opportunities.

\section{Stage Two findings: barriers to benefit capture}

The second stage of the analysis sought to establish a shared network view on the barriers that limit the network actor's ability to capture the benefit opportunities from the product-use data. The focus group identified and prioritised a range of overarching barriers, with several individual manifestations playing out on the firm level, relational level or network level of analysis. 


\section{The barriers}

\section{Inhibiting culture}

The focus group prioritised an inhibiting culture as the most important overarching barrier that stands in the way of actors capturing the product-use data's diverse benefit opportunities. The term 'culture' was used as an overarching concept to summarise diverse inhibiting attitudes and practices that manifest themselves at different levels of the business network.

'Short-term management culture' and 'resistance to change' were identified as firm-level manifestations of the inhibiting culture barrier. Participants' descriptions focused on the transport operator's 'short-term management culture', arguing that "operators are constantly in firefighting mode [with] no time to look forward". "[Their] priority is to get the load out" which limits their attention towards developing the strategic capabilities required to create the benefits from the product-use data. Similarly, participants described how operators were often reluctant to conduct the change management practices required to capture the productuse data's full potential (e.g. introduce driver incentive schemes to increase fuel-efficient driving).

Descriptions of the 'communication difficulties' between network actors were identified as relational-level manifestations of this cultural barrier. Participants explained how significant differences in the digital mindsets among network actors hampers the exploration of joint opportunities based on shared product-use data ('the 'speak' is very geeky, it needs to appeal to a very wide audience in terms of experience"). Participants also pointed to an overall 'antagonistic culture' among the actors, a network level manifestation of the cultural barrier. They explained that traditionally, firms in the road transport industry engage in intensive price-based negotiations which limit efforts to collaboratively develop and exploit network resources.

\section{Lack of digital exchange standards}

A lack of digital exchange standards (the absence of a general consent on data formats and practices) was prioritised by the focus group as the second most important barrier impeding the network actor's ability to capture the benefit opportunities the product-use data provides. Participants specifically pointed to the absence of open exchange practices among the network actors (a relational level manifestation). As actors limit their exchanges to productuse data subsets or aggregations, the benefits other actors derive from it are limited. Participants also described the lack of agreed data format and measurement standards as a 
network-level barrier to benefit capture as it creates additional transformation efforts and reduce data reliability hereby limiting the benefit capture opportunities of all network actors.

\section{Business value uncertainty}

Uncertainty over the business value and business risks was prioritised as the third most important barrier that stands in the way of capturing the benefit opportunities of product-use data. The absence of reliable models and common practices for agreeing on value and risk affects the network levels in different ways. Focus group participants described firm-level 'value uncertainty' manifestations by referring to the difficulties firms face when estimating the benefits that product-use data creates. Their operational diversity and the absence of ROI models constrains investment in infrastructure and capabilities which, in turn limits the data creation and benefit creation efforts of network actors. Participants also described the 'uncertainty over value distribution', as relational-level manifestations of the value uncertainty barrier. Firms are uncertain about how to equitably apportion the value the shared resource provides, which limits the willingness to share benefits with each other. Transport operators, in particular, call for assurances over the equitable distribution of value from the product-use data they create.

\section{Resource limitations}

Resource limitations were prioritised as the fourth most important barrier limiting the ability to create benefit opportunities from product-use data. The focus group participants' descriptions highlighted the 'limited financial and analytical resources' as firm-level manifestations, as particularly transport operators lack the analytical skills and investment required to create the benefits. Investment demands from other business areas are regularly prioritised as more critical ("other demands on same money pot of the business"). But the participants also focused on the 'resource imbalance' across the wider network, which limits the benefit capture opportunities for all network actors. The substantial imbalance between levels of analytical expertise and the considerable diversity of operational practices among network actors create substantial network-wide support needs, which, if unmet, limit the product-use data creation as well as the benefits that can be derived from it.

A further range of barriers the focus group identified (e.g. an excessive number of available systems, a lack of joined-up offerings among actors, limited integration with road transport customers) were, in the end, not prioritised highly by the focus group's participants. 


\section{Impact areas}

The barriers to capturing benefits from product-use data and their individual manifestations were further analysed to discover the specific nature of their limiting impact.

Data processes

Several of the identified manifestations were found to limit the benefit capture opportunities by impacting the underlying data-related processes (creation, sharing). The 'lack of agreed data format and measurement standards', for example, limits the benefit capture opportunities by impacting the data creation (and its sharing). It obstructs the effective build-up of a coherent and comprehensive network resource with knock-on effects for subsequent benefit capture opportunities. The data sharing process emerged as the limiting impact of several other manifestations. Technically focused manifestations, such as the 'lack of agreed data format and measurement standards' (discussed above), the 'absence of open exchange practices', as well as organisationally focused manifestations (such as an 'antagonistic transactional culture' and 'communication difficulties') were found to impact the benefit capture by limiting the sharing of product-use data.

\section{Benefit processes}

Other manifestations the focus group participants identified as limiting the benefit capture opportunities of product-use data were found to impact the benefit-related processes (creation, sharing). The point of benefit creation from data was identified as the point of impact several manifestations limiting the benefit capture. The 'resistance to change', 'resource imbalance' and the lack of 'financial and analytical resources' limits the benefit creation even for cases where the product-use data as a shared network resource is available. Benefit sharing emerged as a further point of impact of other manifestations that limit the network actor's opportunity for benefit capture. The 'uncertainty over value distribution', for example, highlights the contractual difficulties of equitably sharing benefits from one actor, who creates benefits from data, to another actor, who cannot create benefits from data, but contributes to the shared network resource. The 'antagonistic transactional culture' further limits the development of benefit sharing agreements. 


\section{Stage Three findings: eliciting network capabilities required}

The third stage of the research sought to identify the network capabilities required to overcome the barriers and diverse manifestations identified in the second stage. The findings address different facts of the IoT network capability required.

\section{Analytical capability}

The Delphi panel emphasised the analytical capability (capacity to interpret the data) as a critical network capability required to enhance the capturing of benefits from product-use data. The panel's recommendations specifically focused on the importance of developing the analytical capability of firm-level product users (i.e. transport operators) to capture the benefits. Interestingly, the panel not only proposed structured training to upskill the managers but also training to develop the digital skills of the wider workforce (i.e. drivers): to capture the benefit opportunities, it is critical that the wider workforce understands and participates in the required transformation. In particular, it was highlighted that, for drivers to accept that their performance is judged and rewarded on the basis of complex algorithms requires a considerable level of transparency and understanding. The panel also described how a structured common training across the industry would create a shared knowledge base that would help mitigate the 'communication difficulties' which stand in the way of network actors exploring shared benefit creation opportunities.

\section{Innovation capability}

The panel also identified the development of an innovation capability as a critical step to foster the development of solutions that counter 'short-term management culture' and 'resistance to change' with their limiting impact. As a concrete firm-level recommendation, the panel targeted the recruitment priorities: firms are suggested to specifically seek to attract younger generation to capitalise on their openness to digital innovation. The panel argued that, in order to create benefits from product-use data, firms need to innovate their organisational practices, which a generational change would facilitate.

\section{Digital Management capability}

The panel further identified the development of a digital management capability as critical specifically to address the 'value uncertainty' and 'uncertainty over value distribution' which limits the development of collaborative arrangement and investments. The recommendations were for firms to develop capacity to develop formal models to systematically direct their investment into tools for data creation and skills for benefit creation. Such models are 
required to develop an understanding of the business value of product-use data to develop formal arrangements for data and reciprocal benefit sharing among network actors.

\section{Leadership capability}

The development of leadership capability as a critical step to capture the benefits from product-use data was further emphasised by the panel. The call for leadership capability specifically focused on the exchange standard barriers and their network-level manifestations ('lack of agreed data format' and 'measurement standards'). As a concrete recommendation, the panel members highlighted the role of the government in the development of relevant standards ${ }^{4}$. It should leverage its influence as a critical data user by developing clear data standards across a range of its use cases, which would provide the wider network with a focal point to consolidate their efforts. As another concrete recommendation, the panel highlighted the need to set up a consortium which should include manufacturers, operators, digital providers and relevant government agencies to balance out diverse interests and to integrate different perspectives. It would provide the network-level leadership capability required to facilitate and coordinate the common standards creation efforts.

\section{Discussion}

This study set out to explore the particular role and theoretical implications of product-use data in an industry 4.0 network context. By drawing on the case of an emergent UK road transport network, the study first identified the range of benefit opportunities the product-use data provides to the different network actors before pinpointing the resource aspects that explain how these benefit opportunities are created. The findings show that despite the actors' shared dependence on the product-use data as a network resource, they differ with regard to the benefit opportunities they draw from it. Differentiation between access to raw and processed data and between core and peripheral data was identified as a resource aspect that plays a particular part in the creation of these benefit opportunities.

The second research question sought to identify the barriers that stand in the way of the network actors capturing the benefit opportunities from the product-use data resource and identifying the specific nature of the impact these barriers create. The study identified different overarching barriers with a diverse set of individual manifestations, each having a

\footnotetext{
${ }^{4}$ UK transport operators will have the opportunity to integrate some of their performance and operations data with the Driver and Vehicle Standards Agency (DVSA) to minimise disruptive on-road vehicle inspections.
} 
distinct limiting impact at specific levels of the business network. Importantly, while the different manifestations essentially limit the network actors' opportunities for capturing benefits from product-use data, we identified differences in the nature of their impact by showing how some manifestations limit the creation or sharing of data, while others limit the creation or sharing of benefits.

To address the third research question, the study used a Delphi panel to identify how a range of critical network capabilities could overcome the barriers to benefit capture and their individual manifestations. The network capabilities identified include firm-level capabilities which individual network actors require to foster their ability to capture the benefits from the product-use data. These include the relational-level capabilities network actors need to codevelop to facilitate their data and benefit sharing. Finally, they include the network-level capabilities network-level actors need to cooperatively establish to shape their overall business network and thereby facilitate individual actors' opportunities for benefit capture.

\section{Contributions \& future research}

\section{Theoretical contributions}

Advancing the business network perspective for the industry 4.0 context

One of the study's core theoretical contributions lies in the conceptualisation of the industry 4.0 context as an 'emergent business network' and the adoption of a business network perspective for its analysis. The conceptualisation highlights the ambiguities of the roles and relationships of the IoT based network members whose connected relationships positions them as collective actors (Inkpen and Tsang 2005; Anderson, Håkansson, and Johanson 1994, 2). The business network perspective introduces an analytical lens to the industry 4.0 context which highlights the diverse analysis levels (firm, relational, network) to characterise the network (Ramos et al. 2013; Snehota and Hakansson 1995; Welch and Wilkinson 2002). The introduction of the business network perspective provides an opportunity to develop a holistic understanding of the IoT network complexity and to recognise how fundamental issues cut across the network but may manifest themselves at different levels in different forms.

Conceptualising the industry 4.0 context and specifically the IoT technology platform as a business network also highlights the interdependences among the network actors. While other studies explore the IoT implications from the perspective of an individual firm (Porter and Heppelmann 2014; Li, Da Xu, and Zhao 2015; Stojkoska and Trivodaliev 2017; Fatorachian 
and Kazemi 2018), we show how individual firms fulfil distinct interdependent roles (as creators of product-use data or business benefits) which, in turn, affects each firm's opportunities for benefit capture. Hence, our adoption of the business network perspective introduces an important multi-stakeholder understanding into the emerging body of industry 4.0 research.

\section{Product use data and RDT}

Another important theoretical contribution of the present study lies in the conceptualisation of product-use data as the critical network resource that underlies the benefit opportunities actors draw from the IoT based networks. By conceptualising the product-use data as a resource, the study highlights its specific resource attributes (e.g. low external and high internal fungibility) and hereby extends the tool and capability focus of current management research theorising on resources (Wade and Hulland 2004; Otto 2015). More specifically, our study establishes product-use data as a shared network resource (Lavie 2006), emphasising actors are dependent upon other different actors to derive their benefit opportunities.

Our characterisation of the nature and implications of product-use data also creates implications for the application of RDT to the Industry 4.0 context. We show how productuse data, as a shared network resource challenges the options, established RDT emphasises that firms must manage their external resource dependence (i.e. internalisation and control efforts) as a shared network resource. Internalising and tightly controlling the product-use data would be counter-productive and deteriorate its benefit potential. Hence, our study shows how the RDT scope needs to be expanded from focusing on efforts to control a firm's external resources to efforts to stimulate the creation of external resources to capture the specifics of a firm's resource dependency scenarios in an industry 4.0 context.

\section{Contributing to the network capability framework}

Further, the study contributes to an emerging understanding of the role of capabilities in an industry 4.0 context in two ways. First, unlike most studies, which only focus on the technology-related capabilities required when dealing with IoT, our study highlights the social and organisational capabilities that are essential for firms capturing benefits from product-use data. Second, most studies, including Venkatraman et al (2014), only adopt a firm-level perspective when calling for research on IoT based network capabilities. Our network capability adoption incorporates the relational- and network-level capabilities that 
are required to develop and shape the IoT based network environment that allows the individual firm to benefit.

\section{Managerial contributions}

The present study also creates a range of managerial contributions. The network capabilities identified in Stage Three of the research outline concrete initiatives that can be taken to advance firms' ability to capture the benefits from an IoT based network. Specific firm-level recommendations highlight the need for cultural change across the hierarchies through recruitment and targeted training. Although the industry 4.0 context is often portrayed as a technological challenge, firms need to innovate their management practices and business models to capture its benefit opportunities. Relational level recommendations highlight the need for firms to establish clear exchange mechanisms and to showcase each other's capabilities and overcome outdated perceptions. Network level recommendations highlight the need for the development of standards and network leadership to facilitate the environment in which the firms operate. As manufacturing and transport are among the industries where IoT technology is expected to have the biggest financial implications (McKinsey Global Institute 2015), and are also among the industries with the highest skills and resource differential among individual firms (Hamelin 1999), these recommendations are highly relevant.

Furthermore, the study suggests that the industry 4.0 context requires managers to extend their scope beyond their firms and carefully consider how to balance their firms' interests with the interests of the overall network. Given the fickle nature of these emergent business networks, ensuring that the capture of benefits in business networks is balanced and equitable and that networks are therefore not dominated by individual actors becomes critical (Lyytinen, Yoo, and Boland Jr 2016; Inkpen and Tsang 2005).

\section{Limitations of this study}

Despite the range of this study's contributions to the field, it is also important to note its limitations. First, by integrating different methods in the research, the study also integrates their inherent limitations. The focus group method, for example, is sensitive to participants' interactions, and the contributions provided early in the group process can overshadow the further elicitation process (Sutton and Arnold 2013). As a consequence, the identification of overarching barriers by groupings of cards are the result of dynamic interactions among 
participants and are not based on systematic clustering efforts. Although these dynamic interactions provide important opportunities to elicit diverse perspectives, the emerging data and themes are open-ended and may be subject to conceptual overlaps (Gibbs 1997). The Delphi method involves the inherent risk of creating specific topic-related information instead of consolidated generalizable insights (Hsu and Sandford 2007). The present study outlines the specific insights created but also provides a higher-level interpretation and analysis to increase the findings' applicability and theoretical contribution. Although a variety of recommendations were elicited, greater panel diversity might have generated further recommendations.

Second, a qualitative approach in the form of a single case was adopted to investigate the barriers and their implications. While the single case research provides significant opportunities for creating in-depth detailed descriptions (Darke, Shanks, and Broadbent 1998), it limits the generalisability of the findings (Yin 1994). Third, the study's focus, the road transport industry, is singled out in the literature for its lack of IT innovation (Sternberg, Prockl, and Holmström 2014) and overall fragmentation (Hamelin 1999; Todd 2017). While it is important for industry 4.0 research to focus on traditional industries, their specific digitalisation development and interaction practices need to be considered. As technology adoption and utilisation practices depend on previous exposure (Jeyaraj, Rottman, and Lacity 2006), the findings should be verified in other industries to confirm their wider applicability.

\section{Future research}

Our study opens up several concrete opportunities for future research. Of particular interest is the governance of these emergent IoT based networks, where no formal control is exercised (Raab and Kenis 2009); the literature commonly considers resource ties, activity links and actor bonds as governance mechanisms in these networks (Snehota and Hakansson 1995). As the present study already sheds light on the resource ties in the industry 4.0 context, significant opportunities remain for future research to focus on activity links (operational connections and mutual adaptations) and actor bonds (relationships and mutual perceptions) to further advance the understanding of network governance in the industry 4.0 context. Some of the recommendations identified in Stage Three of the research already indicate such critical activity links (i.e. standards development and consortium formation) and actor bonds (i.e. targeted training to broaden understanding roles and sharing risks) and could serve as a starting point for examining these governance mechanisms. 
Future research should also expand the investigative scope by examining the network concept in different business domains and investigate the further kinds of networks currently appearing. The current road transport case represents a comparatively accessible network structure as the limited and transparent exchange of data and benefits provide a natural boundary to identify a network scope and analyse its members' exchanges. Future research that investigates the industry 4.0 context within other industries (e.g. advanced manufacturing) is likely to face more complex network structures, member roles and mutual interdependencies. Such environments where data and benefits are exchanged across potentially far-flung contributors provide opportunities for future research to extend the conceptualisations of product-use data as a shared resource to the context of 'systems' (Cao et al. 2016), or 'systems of systems' (Nielsen et al. 2015). Further, the current digitalisation efforts bring about new kinds of open data networks where multiple stakeholders make their data openly available to stimulate collaboration and innovation (e.g. smart cities, Azahara 2017). The mechanisms and strategies required for governing these forms of networks will be important areas for future research.

Another area for future research is the further development of our understanding of IoT network capabilities. Dynamic capability theory (i.e. the ability to change capabilities) (Winter 2003) has recently become a critical theme in business network research (Zhang and $\mathrm{Wu} 2017$ ) and is likely to be of importance in the context of fast-moving IoT-based networks.

A focus on dynamic capabilities would create an important new analytical perspective on IoT networks: at the firm level, an analysis of dynamic capabilities would not just focus on the firm's ability to respond to network changes but would also capture the firm's ability to perform different roles in different networks, adjust its position in the value chain and deal with threats of lock-ins; at the network level, an analysis of dynamic capabilities would examine the network's ability to adjust and reconfigure itself to accommodate critical changes, and develop and maintain the necessary trust on the network-level. In a dynamic industry 4.0 context, where continuously new standards, new dominant players and new regulations emerge, investigating a network's ability to deal with these changes would constitute an important opportunity for future research. The present conceptualisation of the industry 4.0 context as a business network and product-use data as the core network resource provides the foundation for these future research opportunities. 


\section{References}

Agrifoglio, Rocco, Chiara Cannavale, Elena Laurenza, and Concetta Metallo. 2017. "How emerging digital technologies affect operations management through co-creation. Empirical evidence from the maritime industry." Production Planning \& Control 28 (16):1298-306.

Anderson, James C, Håkan Håkansson, and Jan Johanson. 1994. "Dyadic business relationships within a business network context." The Journal of Marketing 58 (4):115.

Andersson, Per, and Lars-Gunnar Mattsson. 2015. "Service innovations enabled by the "internet of things"." IMP Journal 9 (1):85-106.

Äyväri, Anne, and Kristian Möller. 2008. "Understanding relational and network capabilities-a critical review". Paper presented at the 24th IMP conference in Uppsala, Sweden.

Bae, Jonghoon, and Martin Gargiulo Insead. 2004. "Partner substitutability, alliance network structure, and firm profitability in the telecommunications industry." Academy of Management Journal 47 (6):843-59.

Baines, Tim, and Howard Lightfoot. 2013. Made to serve: How manufacturers can compete through servitization and product service systems. Chichester, UK: John Wiley \& Sons.

Baines, Tim, Ali Ziaee Bigdeli, Oscar Bustinza, Victor Shi, James Baldwin, and Keith Ridgway. 2017. "Servitization: Revisiting the state-of-the-art and research priorities". International Journal of Operations \& Production Management 37 (2):256-278.

Barney, Jay. 1991. "Firm resources and sustained competitive advantage." Journal of Management 17 (1):99-120.

Bello, Oladayo, and Sherali Zeadally. 2016. "Intelligent device-to-device communication in the internet of things." IEEE Systems Journal 10 (3):1172-82.

Benito Azahara. 2017. "How open data helps create smart cities" Geographica. Accessed 28 February 2019. https://geographica.com/en/blog/open-data-helps-smart-cities/.

Blankenburg Holm, Desiree, Kent Eriksson, and Jan Johanson. 1999. "Creating value through mutual commitment to business network relationships." Strategic Management Journal 20 (5):467-86.

Braganza, Ashley, Laurence Brooks, Daniel Nepelski, Maged Ali, and Russ Moro. 2017. "Resource management in big data initiatives: Processes and dynamic capabilities." Journal of Business Research 70:328-37.

Braun, Virginia, and Victoria Clarke. 2006. "Using thematic analysis in psychology." Qualitative research in psychology 3 (2):77-101.

Brewster, Christopher, Ioanna Roussaki, NIkos Kalatzis, Kevin Doolin, and Keith Ellis. 2017. "IoT in agriculture: Designing a Europe-wide large-scale pilot". IEEE Communications Magazine 55 (9):26-33.

Cao, Guangming, Yanqing Duan, Trevor Cadden, and Sonal Minocha. 2016. "Systemic capabilities: The source of IT business value." Information Technology \& People 29 (3):556-79.

Casciaro, Tiziana, and Mikolaj Jan Piskorski. 2005. "Power imbalance, mutual dependence, and constraint absorption: A closer look at resource dependence theory." Administrative Science Quarterly 50 (2):167-99.

Chang, Kuo-chung, and Chih-ping Wang. 2011. "Information systems resources and information security." Information Systems Frontiers 13 (4):579-93. 
Claro, Danny Pimentel, Geoffrey Hagelaar, and Onni Omta. 2003. "The determinants of relational governance and performance: how to manage business relationships?" Industrial Marketing Management 32(8): 703-716.

Cole, Louise. 2016. "Keeping track." Motor Transport February:28-9.

Coreynen, Wim, Paul Matthyssens, and Wouter Van Bockhaven. 2016. "Boosting servitization through digitization: Pathways and dynamic resource configurations for manufacturers." Industrial Marketing Management 60:42-53.

Crié, Dominique, and Andrea Micheaux. 2006. "From customer data to value: What is lacking in the information chain?" Journal of Database Marketing \& Customer Strategy Management 13 (4):282-99.

D'Aunno, Thomas A, and Howard S Zuckerman. 1987. "A life-cycle model of organizational federations: The case of hospitals." Academy of Management Review 12 (3):534-45.

Dalsace, F., W. Ulaga, and C. Renault. "Fleet solutions: From selling tires to selling kilometers." HEC Paris, Accessed 21 September 2018. http://www.ccmp.fr/collection-hec-paris/cas-michelin-fleet-solutions-from-sellingtires-to-selling-kilometers.

Darke, P., G. Shanks, and M. Broadbent. 1998. "Successfully completing case study research: combining rigour, relevance and pragmatism." Information Systems Journal 8 (4):273-89.

Davis, Gerald F, and J Adam Cobb. 2010. "Resource dependence theory: Past and future." In Stanford's organization theory renaissance, 1970-2000, 21-42. Bingley WA: Emerald Group Publishing.

Dierickx, Ingemar, and Karel Cool. 1989. "Asset stock accumulation and sustainability of competitive advantage." Management Science 35 (12):1504-11.

Donohoe, Holly M, and Roger D Needham. 2009. "Moving best practice forward: Delphi characteristics, advantages, potential problems, and solutions." International Journal of Tourism Research 11 (5):415-37.

Fang, Eric, Robert W Palmatier, and Kenneth R Evans. 2008. "Influence of customer participation on creating and sharing of new product value." Journal of the Academy of Marketing Science 36 (3):322-36.

Fatorachian, Hajar, and Hadi Kazemi. 2018. "A critical investigation of Industry 4.0 in manufacturing: theoretical operationalisation framework." Production Planning \& Control 28 (8):633-44.

Fern, Edward F. 1982. "The use of focus groups for idea generation: The effects of group size, acquaintanceship, and moderator on response quantity and quality." Journal of Marketing Research 19 (1):1-13.

Ford, D , L Gadde, H Hakansson, and I Snehota. 2003. Managing Business Networks. Chichester, UK: John Wiley.

Foulonneau, Muriel, Slim Turki, Géradine Vidou, and Sébastien Martin. 2014. "Open data in Service design." Electronic Journal of e-Government 12 (2):99-107.

Gadde, Lars-Erik, Lars Huemer, and Håkan Håkansson. 2003. "Strategizing in industrial networks." Industrial Marketing Management 32 (5): 357-364.

Gibbs, Anita. 1997. "Focus groups." Social research update 19 (8):1-8.

Grubic, Tonci. 2014. "Servitization and remote monitoring technology: A literature review and research agenda." Journal of Manufacturing Technology Management 25 (1):100-24.

Gulati, Ranjay, and Maxim Sytch. 2007. "Dependence asymmetry and joint dependence in interorganizational relationships: Effects of embeddedness on a manufacturer's performance in procurement relationships." Administrative Science Quarterly 52 (1):32-69. 
Gupta, Manjul, and Joey F George. 2016. "Toward the development of a big data analytics capability." Information \& Management 53 (8):1049-64.

Halinen, Aino, and Jan-Åke Törnroos. 2005. "Using case methods in the study of contemporary business networks." Journal of Business Research 58 (9):1285-97.

Hamelin, Patrick. 1999. "Social aspects of road transport drivers working hours." In Social aspects of road transport, edited by European Conference of Ministers of Transport, 67-88. Paris, France: OECD Publications.

Hartmann, Philipp Max, Philipp Max Hartmann, Mohamed Zaki, Mohamed Zaki, Niels Feldmann, Niels Feldmann, Andy Neely, and Andy Neely. 2016. "Capturing value from big data-a taxonomy of data-driven business models used by start-up firms." International Journal of Operations \& Production Management 36 (10):1382-406.

Henneberg, Stephan, Stefanos Mouzas, and Pete Naudé. 2006. "Network pictures: Concepts and representations." European Journal of Marketing 40 (3/4):408-29.

Henneberg, Stephan, Peter Naudé, and Stefanos Mouzas. 2010. "Sense-making and management in business networks - Some observations, considerations, and a research agenda." Industrial Marketing Management 39 (3):355-60.

Hillman, Amy J, Michael C Withers, and Brian J Collins. 2009. "Resource dependence theory: A review." Journal of Management 35 (6):1404-27.

Hsu, Chia-Chien, and Brian A Sandford. 2007. "The Delphi technique: Making sense of consensus." Practical assessment, research \& evaluation 12 (10):1-8.

Inkpen, Andrew C, and Eric WK Tsang. 2005. "Social capital, networks, and knowledge transfer." Academy of Management Review 30 (1):146-65.

Jagdev, Harinder S, and K-D Thoben. 2001. "Anatomy of enterprise collaborations." Production Planning \& Control 12 (5):437-51.

Järvensivu, Timo, and Jan-Åke Törnroos. 2010. "Case study research with moderate constructionism: Conceptualization and practical illustration." Industrial Marketing Management 39 (1):100-8.

Jeyaraj, Anand, Joseph W. Rottman, and Mary C. Lacity. 2006. "A review of the predictors, linkages, and biases in IT innovation adoption research." Journal of Information Technology 21 (1):1-23.

Johanson, Jan, and Jan-Erik Vahlne. 2011. "Markets as networks: implications for strategymaking." Journal of the Academy of Marketing Science 39 (4):484-91.

Kallinikos, Jannis, Aleksi Aaltonen, and Attila Marton. 2013. "The Ambivalent Ontology of Digital Artifacts." MIS Quarterly 37 (2):357-70.

Kambatla, Karthik, Giorgos Kollias, Vipin Kumar, and Ananth Grama. 2014. "Trends in big data analytics." Journal of Parallel and Distributed Computing 74 (7):2561-73.

Karimi, Jahangir, Toni M Somers, and Anol Bhattacherjee. 2007. "The role of information systems resources in ERP capability building and business process outcomes." Journal of Management Information Systems 24 (2):221-60.

Kindström, Daniel, and Christian Kowalkowski. 2014. "Service innovation in product-centric firms: A multidimensional business model perspective." Journal of Business \& Industrial Marketing 29 (2):96-111.

King, William R, Varun Grover, and Ellen H Hufnagel. 1989. "Using information and information technology for sustainable competitive advantage: Some empirical evidence." Information \& Management 17 (2):87-93.

Kogut, Bruce. 2000. "The network as knowledge: Generative rules and the emergence of structure." Strategic Management Journal 21 (3):405-25.

Kohtamäki, Marko, Rodrigo Rabetino, and Kristian Möller. 2017. "Alliance capabilities: A systematic review and future research directions." Industrial Marketing Management 68:188-201. 
Kowalkowski, Christian, Heiko Gebauer, Bart Kamp, and Glenn Parry. 2017. "Servitization and deservitization: Overview, concepts, and definitions". Industrial Marketing Management 60: 4-10.

Kuo, Yong-Hong, and Andrew Kusiak. 2018fc. "From data to big data in production research: the past and future trends." International Journal of Production Research.

Landqvist, Maria, and Frida Lind. 2018fc. "A start-up embedding in three business network settings-A matter of resource combining." Industrial Marketing Management.

Lavie, Dovev. 2006. "The competitive advantage of interconnected firms: An extension of the resource-based view." Academy of Management Review 31 (3):638-58.

Laya, Andres, Jan Markendahl, and Stefan Lundberg. 2018. "Network-centric business models for health, social care and wellbeing solutions in the internet of things." Scandinavian Journal of Management 34 (2):103-16.

Li, Shancang, Li Da Xu, and Shanshan Zhao. 2015. "The internet of things: a survey." Information Systems Frontiers 17 (2):243-59.

Lin, Shin-Wan, and Bradford Miller, (2015). "Industrial internet reference architecture". Technical report by the Industrial Internet Consortium (IIC). Accessed 25 February 2019. www.iiconsortium.org/IIRA-1-7-ajs.pdf.

Lyytinen, Kalle, Youngjin Yoo, and Richard J Boland Jr. 2016. "Digital product innovation within four classes of innovation networks." Information Systems Journal 26 (1):4775.

Marjani, Mohsen, Fariza Nasaruddin, Abdullah Gani, Ahmad Karim, Ibrahim Abaker Targio Hashem, Aisha Siddiqa, and Ibrar Yaqoob. 2017. "Big IoT data analytics: architecture, opportunities, and open research challenges." IEEE Access 5:5247-61.

Matthyssens, Paul, Koen Vandenbempt, and Sara Weyns. 2009. "Transitioning and coevolving to upgrade value offerings: A competence-based marketing view." Industrial Marketing Management 38 (5):504-12.

McGrath, Helen, and Thomas O'Toole. 2010. "The potential and challenge of the network realization capability for SMEs in Ireland and Finland." Journal of Business Market Management 4 (1):27-49.

McKelvey, Bill, Hüseyin Tanriverdi, and Youngjin Yoo. 2016. "Complexity and Information Systems Research in the Emerging Digital World (Call for Papers)." MIS Quarterly, Accessed 11 September 2018.

http://www.misq.org/skin/frontend/default/misq/pdf/CurrentCalls/MISQ_CALL_Eme rgingDigitalWorld.pdf.

McKinsey Global Institute. 2015. "The internet of things: Mapping the value beyond the hype." McKinsey, Accessed 17 September 2018. http://www.mckinsey.com/businessfunctions/business-technology/our-insights/the-internet-of-things-the-value-ofdigitizing-the-physical-world.

Miles, M. B., and A. M. Huberman. 1994. Qualitative data analysis: An expanded sourcebook. Thousand Oaks, California: SAGE publications, Inc.

Möller, Kristian. 2013. "Theory map of business marketing: Relationships and networks perspectives." Industrial Marketing Management 42 (3):324-35.

Möller, Kristian, and Aino Halinen. 2017. "Managing business and innovation networksFrom strategic nets to business fields and ecosystems." Industrial Marketing Management 67:5-22.

Möller, Kristian, and Arto Rajala. 2007. "Rise of strategic nets-New modes of value creation." Industrial Marketing Management 36 (7):895-908.

Möller, Kristian, Arto Rajala, and Senja Svahn. 2005. "Strategic business nets - their type and management." Journal of Business Research 58 (9):1274-84. 
Möller, Kristian, and Senja Svahn. 2003. "Managing strategic nets a capability perspective." Marketing theory 3 (2):209-34.

Möller, Kristian, and Senja Svahn. 2009. "How to influence the birth of new business fields-Network perspective." Industrial Marketing Management 38 (4):450-8.

Morgan, David L. 1996. "Focus groups." Annual Review of Sociology 22 (1):129-52.

Nadj, Mario, Harshavardhan Jegadeesan, Alexander Maedche, Dirk Hoffmann, and Philipp Erdmann. 2016. A situation awareness driven design for predictive maintenance systems Paper presented at the European Conference of Information Systems (ECIS), Rome, Italy.

Nason, Robert S, and Johan Wiklund. 2015. "An assessment of resource-based theorizing on firm growth and suggestions for the future." Journal of Management 44 (1):32-60.

Nielsen, Claus Ballegaard, Peter Gorm Larsen, John Fitzgerald, Jim Woodcock, and Jan Peleska. 2015. "Systems of systems engineering: basic concepts, model-based techniques, and research directions." ACM Computing Surveys (CSUR) 48 (2):1-41.

Öberg, Christina, and Tommy Tsung-Ying Shih. 2014. "Divergent and convergent logic of firms: Barriers and enablers for development and commercialization of innovations." Industrial Marketing Management 43 (3):419-28.

Olkkonen, Rami. 2001. "Case study: The network approach to international sport sponsorship arrangement." Journal of Business \& Industrial Marketing 16 (4):309-29.

Opresnik, David, and Marco Taisch. 2015. "The value of Big Data in servitization." International Journal of Production Economics 165:174-84.

Otto, Boris. 2015. "Quality and value of the data resource in large enterprises." Information Systems Management 32 (3):234-51.

Pagani, Margherita, and Catherine Pardo. 2017. "The impact of digital technology on relationships in a business network." Industrial Marketing Management 67:185-92.

Palmatier, Robert W, Rajiv P Dant, and Dhruv Grewal. 2007. "A comparative longitudinal analysis of theoretical perspectives of interorganizational relationship performance." Journal of Marketing 71 (4):172-94.

Peteraf, Margaret A. 1993. "The cornerstones of competitive advantage: a resource-based view." Strategic Management Journal 14 (3):179-91.

Pfeffer, Jeffrey, and Gerald R Salancik. 2003. The external control of organizations: A resource dependence perspective. Stanford, California: Stanford University Press.

Porter, Michael E., and James E. Heppelmann. 2014. "How Smart, Connected Products Are Transforming Competition." Harvard Business Review 92:11-64.

Provan, Keith G, Amy Fish, and Joerg Sydow. 2007. "Interorganizational networks at the network level: A review of the empirical literature on whole networks." Journal of Management 33 (3):479-516.

Raab, Jörg, and Patrick Kenis. 2009. "Heading Toward a Society of Networks: Empirical Developments and Theoretical Challenges." Journal of Management Inquiry 18 (3):198-210.

Ramos, Carla, Catarina Roseira, Carlos Brito, Stephan Henneberg, and Peter Naudé. 2013. "Business service networks and their process of emergence: The case of the Health Cluster Portugal." Industrial Marketing Management 42 (6):950-68.

Rayes, Ammar, and Samer Salam. 2017. "Internet of things (iot) overview". In Internet of Things From Hype to Reality (pp. 1-34). Springer, Cham.

Roden, S, A Nucciarelli, F Li, and G Graham. 2017. "Big data and the transformation of operations models: a framework and a new research agenda." Production Planning \& Control 28 (11-12):929-44. 
Rymaszewska, Anna, Petri Helo, and Angappa Gunasekaran. 2017. "IoT powered servitization of manufacturing-an exploratory case study." International Journal of Production Economics 192:92-105.

Salmi, Asta. 2000. "Entry into turbulent business networks-The case of a Western company on the Estonian market." European Journal of Marketing 34 (11/12):1374-90.

Schroeder, Andreas, and Julia Kotlarsky. 2015. Digital resources and their role in advanced service provision: a VRIN analysis. Paper presented at the Spring Servitzation Conference, Birmingham, UK.

Sinclair, Bruce. 2017. IoT Inc. New York: McGraw-Hill.

Snehota, Ivan, and Hakan Hakansson. 1995. Developing relationships in business networks. London, UK: Routledge

Sternberg, Henrik, Günter Prockl, and Jan Holmström. 2014. "The efficiency potential of ICT in haulier operations." Computers in Industry 65 (8):1161-8.

Stojkoska, Biljana L Risteska, and Kire V Trivodaliev. 2017. "A review of Internet of Things for smart home: Challenges and solutions." Journal of Cleaner Production 140:145464.

Sutton, Steve G, and Vicky Arnold. 2013. "Focus group methods: Using interactive and nominal groups to explore emerging technology-driven phenomena in accounting and information systems." International Journal of Accounting Information Systems 14 (2):81-8.

Todd, Stuart. 2017. "Digitalisation set to 'change road freight forever'." Lloyds Maritime Intelligence, Accessed 12 September 2018. https://www.lloydsloadinglist.com/freight-directory/news/Digitalisation-set-to'change-road-freight-forever'/68402.htm.

Toms, Steve, and Igor Filatotchev. 2004. "Corporate governance, business strategy, and the dynamics of networks: A theoretical model and application to the British cotton industry, 1830-1980." Organization Studies 25 (4):629-51.

Vaia, Giovanni, Erran Carmel, William DeLone, Harald Trautsch, and Flavio Menichetti. 2012. "Vehicle Telematics at an Italian Insurer: New Auto Insurance Products and a New Industry Ecosystem." MIS Quarterly Executive 11 (3):113-25.

Van Den Belt, Henk. 2003. "How to engage with experimental practices? Moderate versus radical constructivism." Journal for general Philosophy of Science 34 (2):201-19.

Venkatraman, N Venkat, Omar A El Sawy, Paul A Pavlou, and Anandhi Bharadwaj. 2014. "Theorizing digital business innovation: platforms and capabilities in ecosystems." Fox School of Business Research Paper:1-28.

Vesalainen, Jukka, and Henri Hakala. 2014. "Strategic capability architecture: The role of network capability." Industrial Marketing Management 43 (6):938-50.

Wade, Michael, and John Hulland. 2004. "The resource-based view and information systems research: Review, extension, and suggestions for future research." MIS Quarterly 28 (1):107-42.

Walter, Achim, Michael Auer, and Thomas Ritter. 2006. "The impact of network capabilities and entrepreneurial orientation on university spin-off performance." Journal of Business Venturing 21 (4):541-67.

Wang, Yichuan, LeeAnn Kung, William Yu Chung Wang, and Casey G Cegielski. 2018. "An integrated big data analytics-enabled transformation model: Application to health care." Information \& Management 55 (1):64-79.

Wassmer, Ulrich, and Pierre Dussauge. 2011. "Value creation in alliance portfolios: The benefits and costs of network resource interdependencies." European Management Review 8 (1):47-64. 
Watson, Richard T, Marie-Claude Boudreau, Seth Li, and Jack Levis. 2010. "Telematics at UPS: En route to energy informatics." MIS Quarterly Executive 9 (1):1-11.

Welch, Catherine, and Ian Wilkinson. 2002. "Idea logics and network theory in business marketing." Journal of Business-to-Business Marketing 9 (3):27-48.

Whitmore, Andrew, Anurag Agarwal, and Li Da Xu. 2015. "The internet of things: A survey of topics and trends." Information Systems Frontiers 17 (2):261-74.

Winter, Sidney G. 2003. "Understanding dynamic capabilities." Strategic Management Journal 24 (10):991-5.

Yin, Robert B. 1994. Case Study Research: Design and Methods. Thousand Oaks, CA: SAGE Publications, Inc.

Yoo, Youngjin, Ola Henfridsson, and Kalle Lyytinen. 2010. "Research commentary-The new organizing logic of digital innovation: An agenda for information systems research." Information Systems Research 21 (4):724-35.

Zhang, Junfeng, and Wei-ping Wu. 2017. "Leveraging internal resources and external business networks for new product success: A dynamic capabilities perspective." Industrial Marketing Management 61:170-81.

This work was supported by the Economic and Social Research Council (ESRC) under Grant Ref ES/P010148/1 'Pathways towards Servitization: A trans-national study of Organisational Transformation. 